\title{
A RESEARCH NOTE ON THE HISTORY OF ITIN'S IMPLEMENTATION AND ADAPTATION IN UNITED STATES TAX ADMINISTRATION
}

Marquise Riley, Brendan Brown, John McKinley, and Eric Lewis

The BRC Academy Journal of Business 9, no. 1 (2019): 129-146.

http://dx.doi.org/10.15239/j.brcacadjb.2019.09.01.ja07

Web APPENDIX

http://dx.doi.org/10.15239/j.brcacadjb.2019.09.01.wa07 
Part A.

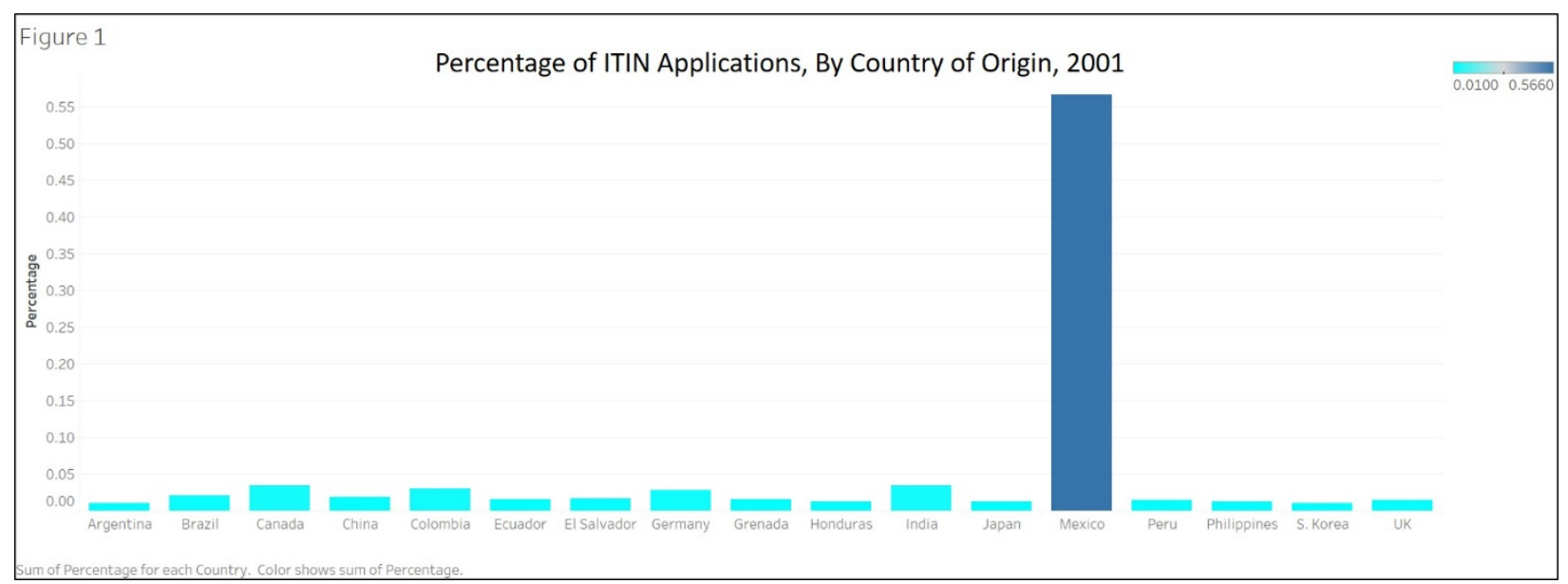

Figure 1

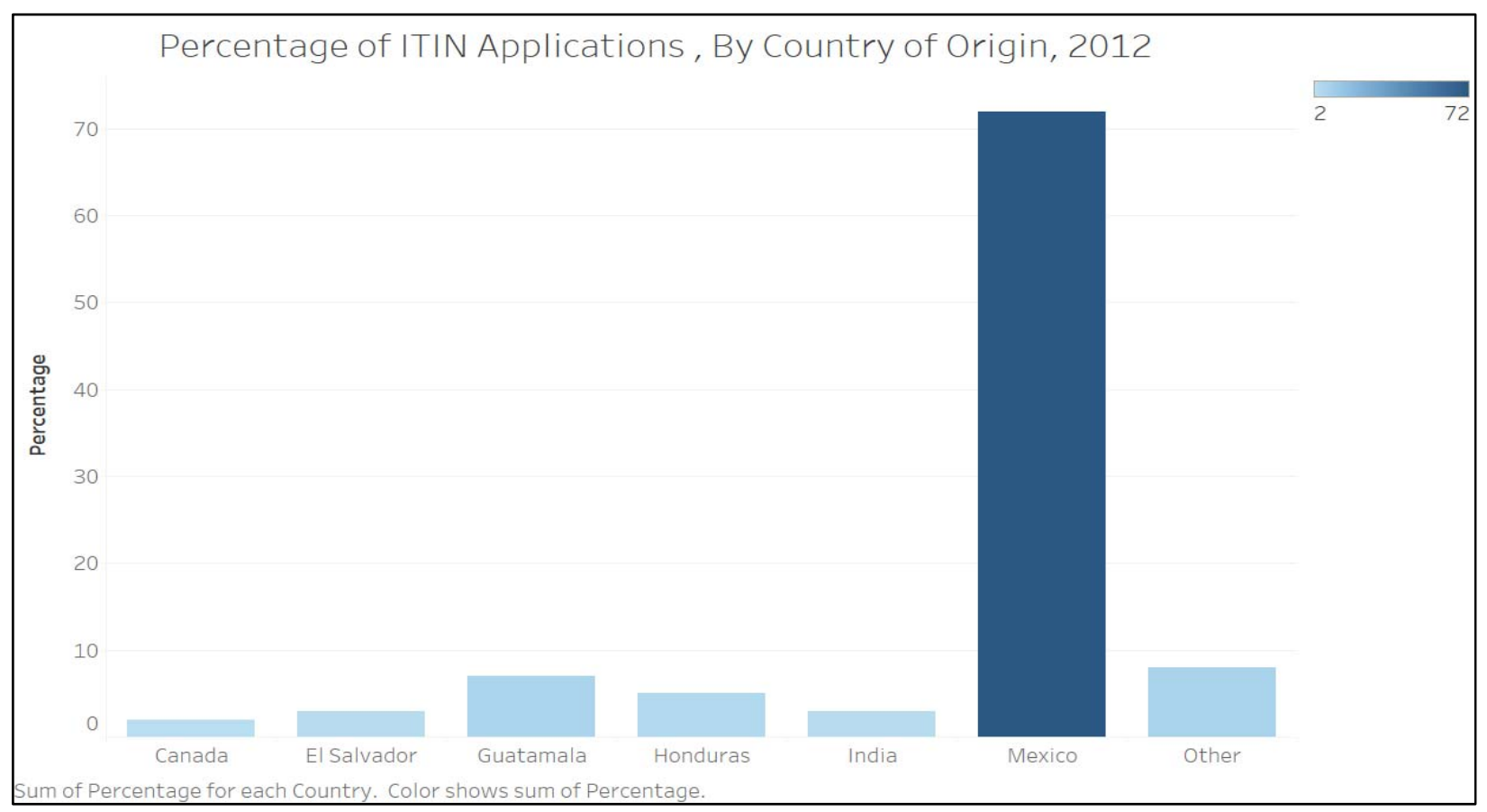

Figure 2 
Part A (Cont.)

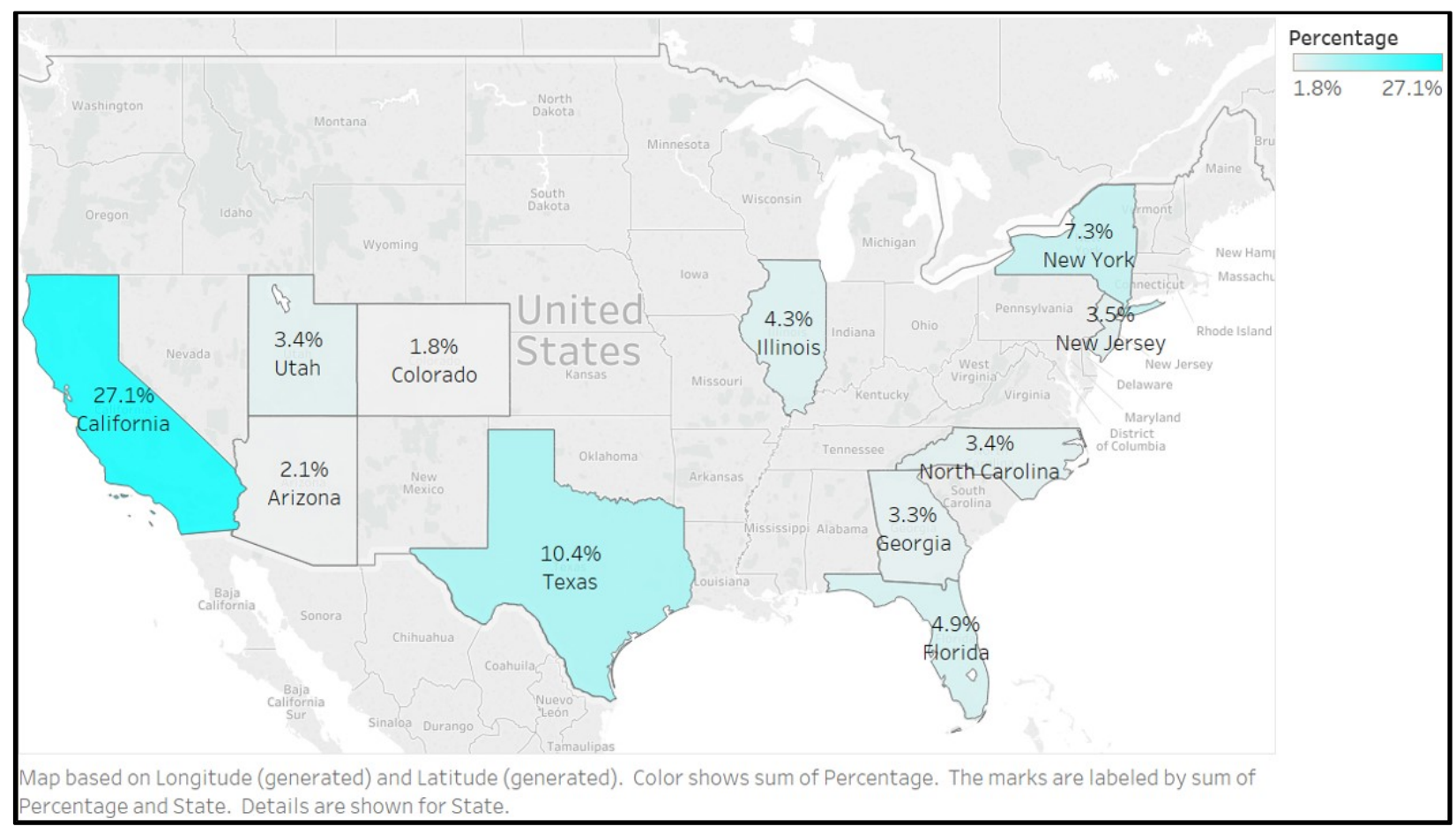

Figure 3 
Part B. Excerpts and Pictures from Form 1040 (1913, 1941, 1942, 1961) with Callouts Highlighting

Relevant Changes to the Forms or other Important Information, Gathered from the IRS' website

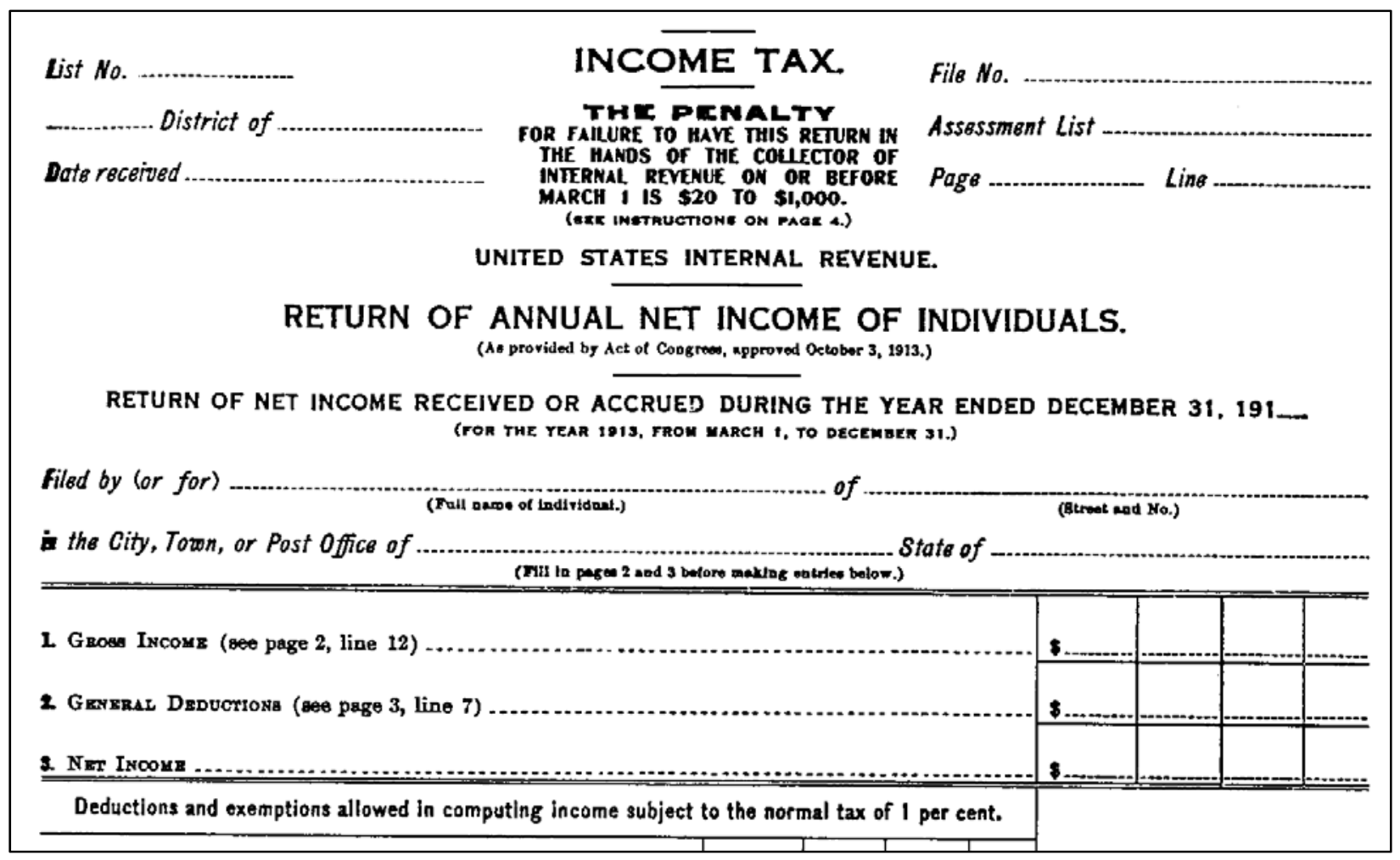

Figure 4

1913 Form 1040

1941 Form 1040

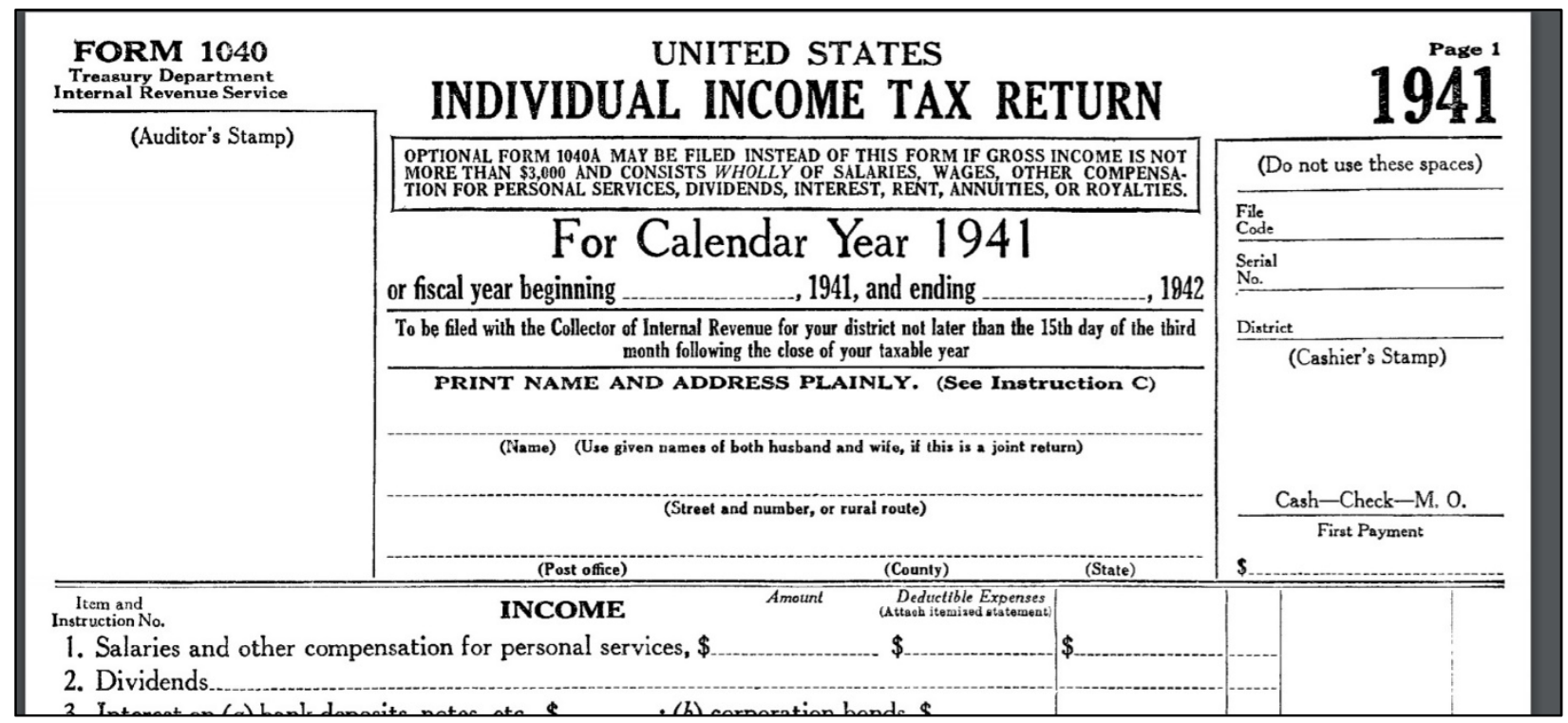

Figure 5 
Part B, Continued

1942 Form 1040

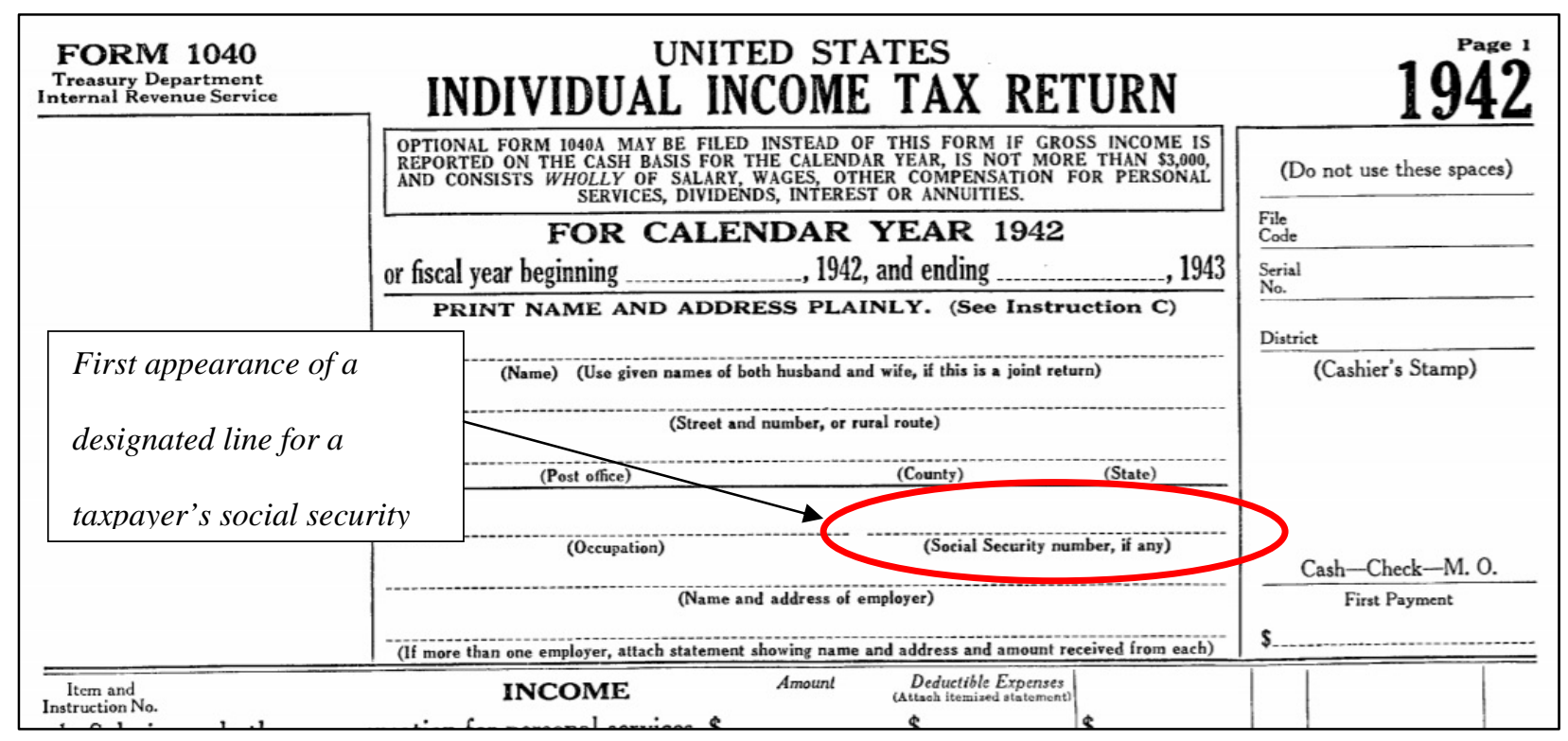

Figure 6 
Part B, Continued

1961 Form 1040 Instructions

\section{HOW TO USE FORM 1040}

In order to make preparation of tax 2-page Form 1040. In such case mercreturns easier for the great majority of ly enter the taxable amount of dividends taxpayers, the individual income tax re- and interest reccived on line 5 of the turn Form 1040 has been revised. The form. In figuring the amount of divimain form is limited to a single sheet. dends to be reportcd, exclude the first Supporting schedules may be attached according to the individual needs of each taxpayer.

If your income was entirly fual savings banks or savings (building) salary and ind on 22-page Form 1040 . You can use it whether you take the standard deduc- had dividend income, each is cntitled at
tion or itemize deductions.
most to a $\$ 50$ exclusion and one may

most to a $\$ 50$ exclusion and one may

If in addition to salary and wages you not use any portion of the $\$ 50$ cxclusion
have not more than $\$ 200$ of dividends not used by the other. For example, if and interest, you also need only file the the husband had $\$ 100$ in dividends, and office.

\section{WAGE EARNERS WITH LESS THAN $\$ 10,000$ INCOME}

You can usc a simpler return (Form 1040A), printed on a punchcard, if: 1. Your income was less than $\$ 10,000, A N D$

2. It consisted of wages reported on withholding statements (Forms W-2) and not more than $\$ 200$ total of other wages, interest, and dividends, ANI

3. You wish to take the standard deduction (about 10 percent of your income) instead of itemizing deductions.

The special instruction sheet for the form provides further information about its use. One of the special features is that if your incorne is less than $\$ 5,000$, you can choose to have the Intcrnal Revenue Service figure your tax for you. You can obtain these form s from most banks and some post offices. the wife had $\$ 20$, only $\$ 70$ may be excluded on a joint return.

If your dividends and interest exceed $\$ 200$, or if you have income from rents, royalties, pensions, annuities, partnerships, estates, trusts, etc., use and attach Schedulc B.

If you have income from a personally owned business, attach Schedule C.

If you have income from the sale or exchange of property, attach Sched-

If you have incom tach Schedule F. These schedules rom any Internal

DIVIDENDS? INTER Be sure to report all of

all sources. Some ta Tax Return containing a reporting income from principal sources, tend lesser amounts from interest on savings ac interest, dividends, and when such amounts are accounts rather than rece accuracy in reporting th benefit both you and

The Instructions for the

1961 Form 1040 Income passage explaining the IRS intended use for taxpayers'

action that might otherw

\section{IMPORTANCE OF SOCIAL SECURITY NUMBERS}

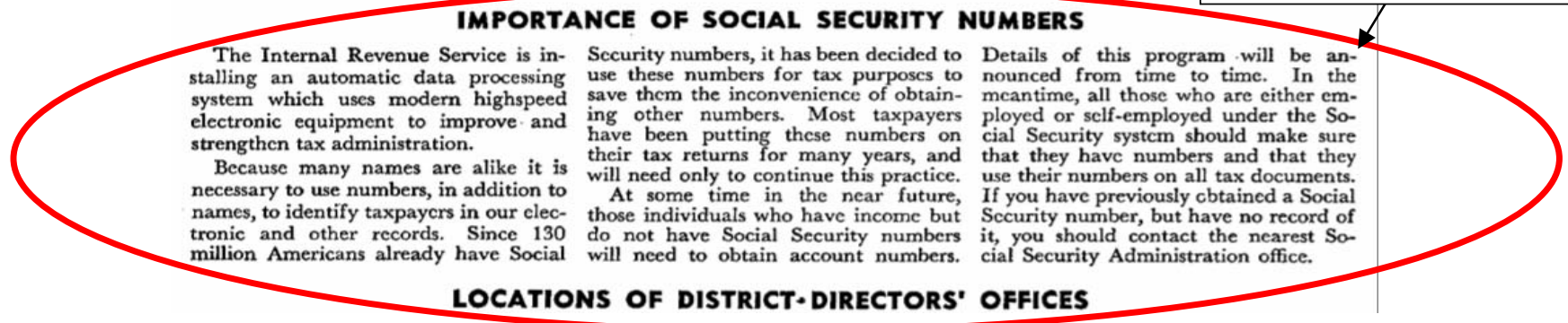

Figure 7 